\title{
PARTIDOS POLÍTICOS, ÉLITES PARLAMENTARIAS Y CLASES SOCIALES EN CENTROAMÉRICA*
}

\author{
Manuel Alcántara Sáez e Iván Llamazares Valduvieco
}

\section{INTRODUCCIÓN}

Este artículo analiza algunas características sociodemográficas básicas de las élites parlamentarias de cuatro países centroamericanos (El Salvador, Nicaragua, Honduras y Costa Rica). Dichas características se refieren especialmente a la procedencia social y las experiencias políticas de los parlamentarios de estos países, así como a algunas actitudes culturales y políticas básicas (creencias religiosas y autoidentificación ideológica) de los mismos. Precisamente, un análisis de la forma en la que tales características se combinan en cada partido político puede ayudarnos a identificar algunos tipos básicos de partidos políticos en la región centroamericana.

Numerosos estudios sobre las élites parlamentarias han confirmado la presunción de que los miembros de estas últimas proceden, casi siempre de manera desproporcionada, de los sectores sociales y económicos más altos de la sociedad (Matthews, 1985). Ahora bien, es también conocido el hecho de que el grado en que las élites parlamentarias presentan características sociales y económicas "elitistas" (y esta redundancia remite a una diferencia, constante en este artículo, entre el concepto de élites socioeconómicas y el de élites parlamentarias) no es idéntico en los distintos países, partidos y fases históricas, y que la profesionalización de la élite parlamentaria va asociada a una limitación de la presencia en esta última de las clases más acomodadas (Best, 1995; King, 1981; Eliassen, 1995; Ruostetsaari, 1995).

En este artículo, intentamos establecer algunas de las variaciones nacionales y de partido más significativas en este sentido. La razón de esta indagación tiene que ver, en primer lugar, con nuestro interés en comprender las implicaciones que determinados factores causales (como las trayectorias políticas de cada país, su vida institucional o su desarrollo socioeconomico) han tenido para la conformación de las élites parlamentarias y de los respectivos sistemas de partidos de estos países.

En segundo lugar, este análisis pretende contribuir a clarificar algunas de las connotaciones sociales de los partidos y los sistemas de partidos de la región. Si bien es cierto que los diputados no reflejan con entera fidelidad las características de los partidos, sí que se puede afirmar que aquellos representan una esfera fundamental de los mismos; al menos durante el periodo de su mandato, los diputados son el elemento más estable y políticamente relevante de los partidos. Por este motivo, este análisis pretende aportar algunos elementos de juicio a la comprensión de los condicionantes del proceso de consolidación democrática en las sociedades centroamericanas mediante el estudio de esos sectores políticos.

En último término, un objetivo de esta investigación consiste en establecer en qué medida existen vínculos entre los orígenes sociales de los diputados, sus orientaciones político-ideológicas y las trayectorias históricas de cada sociedad centroamericana.

Por lo tanto, este estudio comparado de las élites parlamentarias de cuatro países centroamericanos integra varias discusiones teóricas. La primera remite a la evaluación, siguiendo el ya clásico estudio de Putnam acerca de los parlamentarios británicos e italianos, de las complejas vinculaciones existentes entre contexto sociopolítico, experiencias de los parlamentarios, ideas políticas, acción política y regímenes políticos (Putnam, 1973). En particular, este trabajo analiza la importancia de la clase social en este terreno. Como es sabido, el estudio de Putnam estableció la importancia de la clase social a la hora de explicar las diferentes actitudes (igualitarias y autoritarias) de los diputados italianos y británicos.

En segundo lugar, los objetivos de esta investigación se relacionan con el análisis de la vinculación general que existe entre los procesos de desarrollo económico y cambio social de cada sociedad y las características de su élite parlamentaria. Un análisis de este tipo permitirá evaluar la validez que las descripciones generales acerca de los proce-

Este trabajo se inserta en la investigación financiada por el Plan Nacional de Ciencia y Tecnología (Referencia SEC 95-0845) acerca de los congresistas latinoamericanos. Todas las entrevistas que se recogen aquí fueron realizadas entre julio y noviembre del año 1994. Una versión anterior de este trabajo fue presentada en el I Congreso Europeo de Latinoamericanistas, celebrado en la Universidad de Salamanca de los días 26 a 28 de junio de 1996. 
sos de diferenciación y profesionalización de la élite política en las sociedades contemporáneas tienen para las sociedades centroamericanas, así como establecer contrastes significativos entre los países analizados aquí.

Por último, este análisis se enmarca dentro de las discusiones que relacionan la representación de los distintos actores sociales dentro del sistema de partidos con la viabilidad de los regímenes democráticos. Por un lado, ciertos autores han señalado que los riesgos de un desenlace autoritario son más altos cuando en el sistema de partidos no está presente al menos un partido importante, con posibilidades de victoria electoral, que represente adecuadamente los intereses de las clases altas (Rueschemeyer, Huber Stephens y Stephens, 1992). Por otro lado, la exclusión de la arena política de los representantes de los actores sociopolíticos que suponían algún tipo de reto al sistema de poder económico social prevalente en las sociedades centroamericanas ha sido uno de los factores obvios de la polarización política de dichas sociedades y de la inestabilidad consiguiente que han experimentado las mismas. Por consiguiente, tiene sentido evaluar la forma en que, como resultado de los procesos políticos más recientes, las élites parlamentarias de estas sociedades han pasado a representar a los distintos sectores económicos y sociales. de que se articulara correctamente la alternancia entre las dos familias políticas más significativas: los liberales y los nacionales. En ambos países el bipartidismo se ha asentado sólidamente llegando a generar auténticas subculturas. En los casos de El Salvador y Nicaragua, si bien el periodo autoritario previo a la década de 1980 tuvo unas características diferentes definidas por el carácter más cleptocrático impuesto por la saga Somoza en Nicaragua, la tensión de guerra civil y de contraposición entre propuestas revolucionarias dominó la década de 1980. En la actualidad, las reformas constitucionales de la década pasada, junto con el éxito de los procesos de pacificación, han estabilizado el juego político permitiéndose una competencia libre y abierta entre los actores insólita y de dimensión histórica'.

\section{ENTRADA EN POLÍTICA Y POLITIZACIÓN FAMILIAR}

A nuestro juicio, los propósitos de este artículo exigen comprender con precisión las características principales de la entrada en política de los congresistas. En este caso, hemos analizado en primer lugar la edad en la que los diputados centroamericanos entraron en la vida política, así como el nivel de participación política de sus familiares.

TABLA 1. AÑO DE ENTRADA EN POLÍTICA POR PARTIDO POLÍTICO

\begin{tabular}{||l|c|c|c|c|c|c|c|c||}
\hline & PLN & PUSC & PL & PN & FMLN & PDC & ARENA & FSLN \\
\hline AÑO DE ENTRADA EN POL. & 73 & 72 & 73 & 79 & 72 & 76 & 82 & 66 \\
\hline AÑO DE NACIM. & 47 & 47 & 44 & 53 & 51 & 44 & 54 & 46 \\
\hline EDAD DE ENTR. EN POL. & 25 & 25 & 29 & 26 & 21 & 22 & 28 & 20 \\
\hline N & 25 & 23 & 35 & 30 & 15 & 10 & 18 & 18 \\
\hline
\end{tabular}

En este trabajo nos limitamos al análisis comparativo de algunas características de las élites parlamentarias en El Salvador, Honduras, Costa Rica y Nicaragua. Es preciso aclarar aquí que, en este estadio de la investigación, y como resultado de la fluidez y baja institucionalización que caracteriza al sistema de partidos nicaragüense, y de la consiguiente dificultad de ubicar políticamente a algunos de los parlamentarios de aquel país, hemos optado por no incluir en este artículo datos referidos a los partidos nicaragüenses que estuvieron, en su momento, englobados dentro de la Unión Nacional Opositora.

Los países analizados aquí presentan tanto importantes similitudes como fuertes contrastes. Un elemento común que se extiende a todos ellos se refiere a sus reducidas dimensiones tanto físicas, como poblacionales y económicas. Sus economías tienden al monocultivo orientado a la exportación. En el ámbito político, la democracia ha estado únicamente presente, de forma ininterrumpida, en Costa Rica desde 1949 y en Honduras ésta ha tomado una forma fuertemente oligárquica, sin perjuicio
La Tabla 1 muestra que el Frente Sandinista de Liberación Nacional nicaragüense (FSLN), el Farabundo Martí de Liberación Nacional salvadoreño (FMLN) y el Partido Demócrata Cristiano salvadoreño (PDC) son los partidos en los que los congresistas entraron en la vida política a una edad más temprana (con poco más de veinte años de media en cada uno de estos partidos. Por contra, los congresistas de la Alianza Republicana Nacional (ARENA) y el Partido Liberal (PL) de Honduras ingresaron en la vida política en una fase claramente más tardía, cuando se hallaban ya más cerca de la treintena.

1. Para un análisis comparado del contexto social y político de los distintos países centroamericanos, ver Vilas (1994). 
TABLA 2. NÚMERO DE FAMILIARES ACTIVOS EN LA VIDA POLÍTICA (POR PARTIDO POLÍTICO)²

\begin{tabular}{||l|c|c|c|c|c|c|c|c||}
\hline & PLN & PUSC & PL & PN & FMLN & PDC & ARENA & FSLN \\
\hline N. ${ }^{\circ}$ FAMILIARES &, 6 & 1,3 & 1 & 1 & 7 &, 2 & 1 & 1,8 \\
\hline $\mathrm{N}$ & 25 & 23 & 35 & 30 & 15 & 10 & 18 & 18 \\
\hline
\end{tabular}

La Tabla 2 muestra que el número de familiares políticamente activos es muy bajo en el caso del PDC, y bajo en los casos del Partido Liberación Nacional de Costa Rica (PLN) y del FMLN. Por contra, ese número es muy alto en el caso del FSLN y bajo en los casos del Partido Unido Social Cristiano (PUSC), de ambos partidos hondureños y de ARENA.

Si combinamos estos dos criterios, es posible concluir la existencia de interesantes contrastes y similitudes entre estos partidos políticos. En especial, los congresistas de ARENA, el PUSC, y los partidos hondureños combinan niveles relativamente altos de politización familiar y fechas tardías de entrada en política. Esta asociación sugiere que la combinación de esas características puede tener que ver con el carácter elitista de ciertos partidos en esta región. La entrada tardía en la vida política sugiere que la completa participación política sólo se ha desarrollado después de haber iniciado los diputados sus carreras profesionales. Por otra parte, el número de familiares en la vida política da una idea de los recursos políticos familiares y de la inclusión de los diputados en redes políticas a través de la familia. No olvidemos que tradicionalmente se ha resaltado la importancia de las redes familiares en la vida política y social de las élites centroamericanas (Vilas, 1996: 474-475). Por otra parte, el alto nivel de los congresistas sandinistas en esta dimensión puede relacionarse con el hecho de que el FSLN ocupó posiciones de poder durante todo el periodo que siguió a la revolución sandinista.

TABLA 3. EDAD DE ENTRADA EN POLÍTICA Y NIVEL DE POLITIZACIÓN FAMILIAR (NÚMERO DE FAMILIARES EN LA VIDA POLÍTICA)

\begin{tabular}{||l|c|c||}
\hline & $\begin{array}{c}\text { ALTA } \\
\text { POLITIZACIÓN } \\
\text { FAMILIAR }\end{array}$ & $\begin{array}{c}\text { BAJA } \\
\text { POLITIZACIÓN } \\
\text { FAMILIAR }\end{array}$ \\
\hline ENTRADA & ARENA & PLN \\
TARDÍA EN & PUSC & \\
POLÍTICA & PL & \\
\hline ENTRADA & PN & \\
TEMPRANA EN & FSLN & FMLN \\
POLÍTICA & PDC & \\
\hline
\end{tabular}

\section{CLASE SOCIAL}

En nuestra opinión, esta interpretación de la Tabla 3 es confirmada por los datos sobre los orígenes sociales de los congresistas. A pesar de que es presumible que una cierta resistencia de parte de los diputados a situar sus orígenes sociales en los sectores económicos más acomodados, es claro que los diputados del PUSC, de ARENA y de los partidos hondureños revelan orígenes sociales más elevados. Resulta interesante, a este respecto, que todos estos se sitúen en la esquina superior izquierda de la Tabla 3. El PLN de Costa Rica es el único partido cuyos diputados revelan orígenes de clase semejantes a las de los anteriores y que, sin embargo, no está incluido en ese cuadrante. Ello sugiere que dicho partido posee características sociales mixtas o ambiguas en este terreno.

\section{TABLA 4. ORÍGENES DE CLASE3}

\begin{tabular}{|l|c||}
\hline $\begin{array}{l}\text { ORÍGENES } \\
\text { POLÍTICO }\end{array}$ & $\begin{array}{c}\text { PARTIDO } \\
\text { SOCIALES }\end{array}$ \\
\hline PUSC & 2,5 \\
\hline ARENA & 2,6 \\
\hline PN & 2,7 \\
\hline PLN & 2,7 \\
\hline PL & 2,8 \\
\hline FSLN & 3,1 \\
\hline PDC & 3,3 \\
\hline FMLN & 3,4 \\
\hline
\end{tabular}

2. Las presentes diferencias de medias son significativas al nivel del 0.05 .

3. La escala utilizada aquí va del 1 al 4 . En la misma, los números más altos indican un origen de clase más bajo y viceversa. Las diferencias entre las medias de los partidos políticos son significativas al nivel del 0.05 . Las diferencias de medias entre los partidos políticos son especialmente significativas en El Salvador (al 0.02). 
Gráfico 1. Clase social de origen

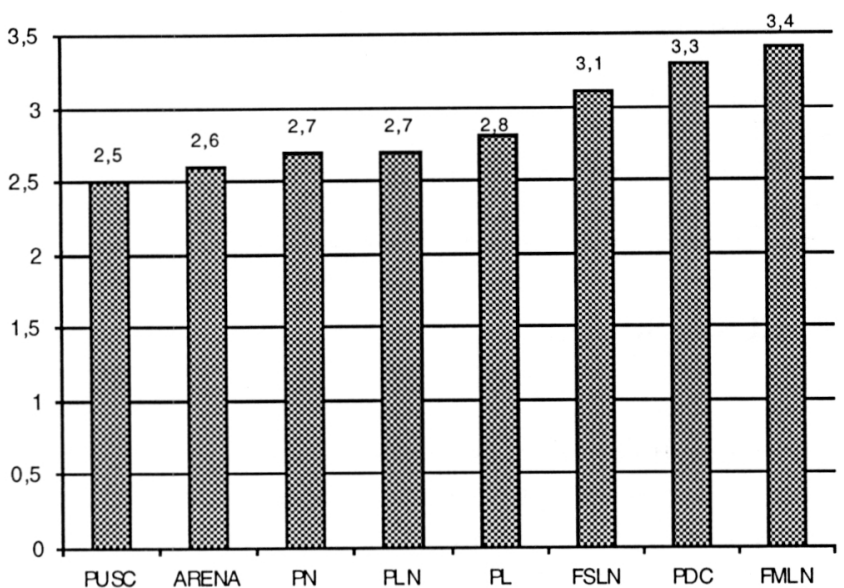

TABLA 5. PROCEDENCIA PROFESIONAL DE LOS CONGRESISTAS ANTES DE CONVERTIRSE EN POLÍTICOS PROFESIONALES (PORCENTAJES POR PARTIDO POLÍTICO)

\begin{tabular}{||l|c|c|c||}
\hline $\begin{array}{l}\text { PARTIDO } \\
\text { POLÍTICO }\end{array}$ & $\begin{array}{c}\text { DERECHO Y } \\
\text { PROFESIONES } \\
\text { LIBERALES }\end{array}$ & EMPRESARIOS & PROFESORES \\
\hline ARENA & 61 & 22 & - \\
\hline FMLN & 7 & - & - \\
\hline PDC & 50 & 10 & 30 \\
\hline PLN & 28 & 16 & 32 \\
\hline PUSC & 44 & 26 & 22 \\
\hline PL & 34 & 40 & 9 \\
\hline PN & 37 & 43 & 7 \\
\hline FSLN & 22 & - & 4 \\
\hline
\end{tabular}

Esta tabla proporciona una idea muy clara del nivel de elitismo y profesionalización de la élite parlamentaria. Del análisis de la misma se desprende que el origen socio-económico es más alto en los partidos más conservadores y elitistas (ARENA, PUSC, ambos partidos hondureños). Dicho origen es más bajo en partidos cuyos congresistas no están fusionados con los estratos más altos de la sociedad (FSLN, PDC, FMLN).

Resulta interesante, en este sentido, que los congresistas del FSLN tengan orígenes de clase más acomodados que los del PDC y el FMLN. Ello puede tener que ver con el hecho de que el régimen de Somoza tenía un carácter claramente sultanista, y que, como tal, generó una oposición de características más multiclasistas. Por ello, el FSLN tendría tanto características propias de los partidos que representan sectores excluidos del sistema de poder social (edad de entrada en política, orígenes de clase más bajos) como rasgos típicos de partidos de clase media y media alta. (nivel de politización, nivel de educación, etc.) ${ }^{4}$.
Gráfico 4. Autoidentificación ideológica

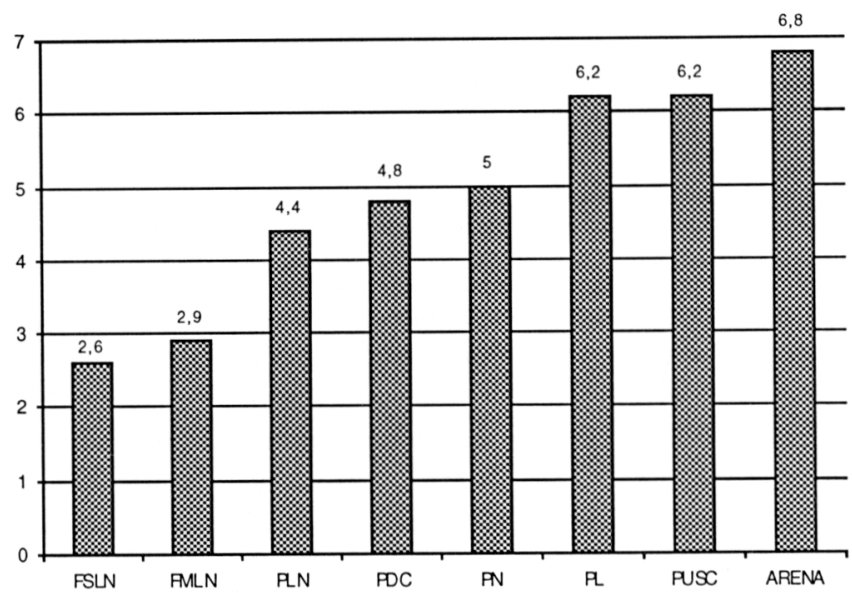

Estas observaciones acerca de los orígenes sociales de los congresistas son confirmadas por el análisis de las ocupaciones de los diputados antes de entrar en el parlamento. Así, la Tabla 5 muestra que los congresistas de algunos partidos integran estratos más altos de la sociedad (ARENA, el PUSC y ambos partidos hondureños). Es revelador el hecho de que estos partidos incluyan altos porcentajes de empresarios. Es especialmente significativo también que ambos partidos hondureños tengan los porcentajes más altos de grandes empresarios. Este último porcentaje llega el $31 \%$ en el caso del PL y al $40 \%$ en el caso del PN. Asimismo, el porcentaje de grandes empresarios dentro del PUSC llega al $22 \%$. Por otra parte, sólo alrededor del $11 \%$ de los congresistas de ARENA son grandes empresarios. Este porcentaje llega al $10 \%$ en el caso del PDC y al $8 \%$ en el caso del PLN.

Por contra, nadie en las filas del FSLN o del FMLN ha tenido una ocupación semejante. Sin embargo, de nuevo el FSLN muestra una presencia más alta de las clases altas y clases medias-altas. Esto se refleja en que el porcentaje de personas que tenían profesiones liberales y relacionadas con el mundo jurídico es tres veces más alto en el caso del FSLN que en el FMLN.

Por último, resulta obvio que el perfil del PLN y del PDC es mucho menos elitista que el de ARENA y los partidos hondureños. En especial, el PLN y el PDC incluyen porcentajes de empresarios mucho menores

\section{CREENCIAS RELIGIOSAS, AUTOIDENTIFICACIÓN IDEOLÓGICA, CLASE Y PARTIDO POLÍTICO}

Resulta especialmente interesante considerar la relación entre los partidos políticos, las actitudes religiosas y el origen social. La Tabla 6 muestra la intensidad de las creencias religiosas de los congresistas centroamericanos.

4. Hay que tener en cuenta que existe una fuerte asociación entre los indicadores de clase social y los de educación entre los diputados centroamericanos. Por ejemplo, la correlación entre orígenes de clase y nivel de educación del padre asciende, para estos diputados, a la cifra de 0,51. 
En ella se aprecia que, en cada país, los encuestados de los partidos de las clases más altas manifiestan tener sentimientos religiosos más intensos que los de las clases más bajas. Además, es muy claro que los encuestados del FSLN y del FMLN poseen actitudes mucho menos religiosas. Así, cuando pasamos de un partido centrista como el PDC salvadoreño al FSLN, observamos una caída abrupta en las creencias religiosas. Esto revela que los líderes de los partidos de izquierda tienen orientaciones escasamente religiosas. Es también interesante el hecho de que exista una ligera diferencia entre estos dos partidos, en la medida en que los congresistas del FMLN se posicionan en el punto más bajo en esta dimensión. En este sentido, se podría argumentar que esta dimensión está igualmente relacionada con las características más o menos elitistas, en términos sociales, de los congresistas de cada partido.

TABLA 6. INTENSIDAD MEDIA DE LAS CREENCIAS RELIGIOSAS POR PARTIDO POLÍTICO (DE 1 A 10)

\begin{tabular}{|l|c|}
\hline $\begin{array}{l}\text { PARTIDO } \\
\text { POLÍTICO }\end{array}$ & $\begin{array}{c}\text { INTENSIDAD DE CREENCIAS } \\
\text { RELIGIOSAS }\end{array}$ \\
\hline ARENA & 7 \\
\hline PUSC & 6,5 \\
\hline PLN & 6,3 \\
\hline PN & 6,2 \\
\hline PL & 5,7 \\
\hline PDC & 5,6 \\
\hline FSLN & 3,1 \\
\hline FMLN & 2,9 \\
\hline
\end{tabular}

Gráfico 3. Intensidad de creencias religiosas

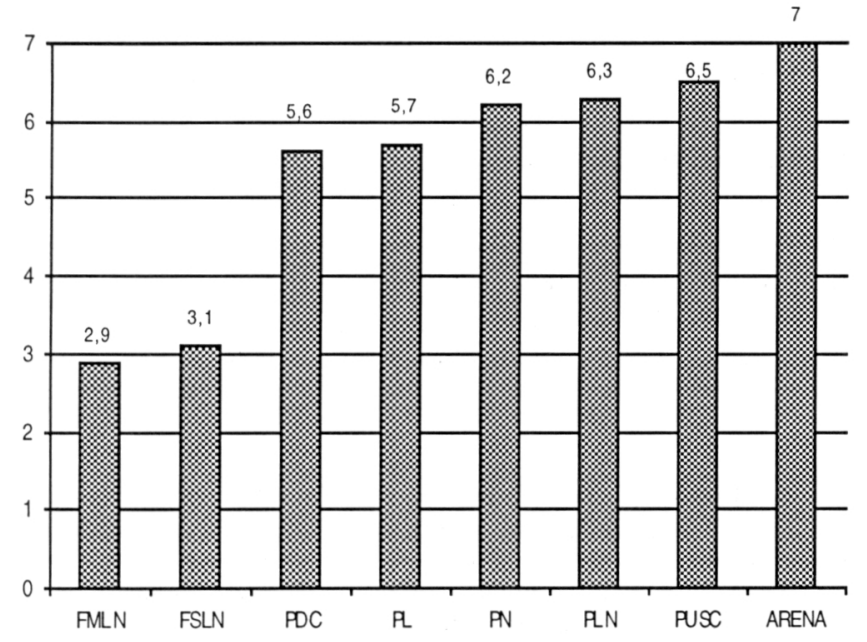

La tabla 7 sugiere que existe una clara conexión entre el nivel de elitismo de los partidos políticos y la intensidad de las creencias religiosas de su élite parlamentaria. Así, es claro que los partidos que se sitúan en los lugares más altos de varios de los apartados socialmente elitistas (como las ocupaciones y la clase social de origen) muestran creencias religiosas especialmente fuertes. Este es claramente el caso de ARENA y del PUSC. Hay dos partidos no elitistas cuyos congresistas se sitúan en posiciones medias o medias altas en la escala religiosa (el PDC y el PLN). Estos últimos muestran, también en otros aspectos, una posición más centrista y de clase media. Finalmente, los congresistas de los partidos claramente hostiles a las élites socioeconómicas (los del FSLN y el FMLN) muestran perfiles religiosos muy bajos. Estas características son igualmente interesantes en la medida en que la Iglesia Católica ha mantenido, en determinados países y circunstancias, posiciones progresistas y socialmente reformistas.

\section{TABLA 7. RELIGIOSIDAD Y ELITISMO (ENTRE PARÉNTESIS FIGURA LA RELIGIOSIDAD MEDIA DE LOS DIPUTADOS DE CADA PARTIDO POLÍTICO)}

\begin{tabular}{||l|c|c||}
\hline & PARTIDO & PARTIDOS \\
& DE ELITES & NO ELITISTAS \\
\hline MEDIA & ARENA (7) & PLN $(6,3)$ \\
ALTA A ALTA & PUSC $(6,5)$ & PDC $(5,5)$ \\
& & PN $(6,2)$ \\
& & PL $(5,7)$ \\
\hline BAJA & & FSLN $(3,1)$ \\
& & FMLN $(2,9)$ \\
\hline
\end{tabular}

Como se observa en la tabla posterior, la autoubicación media de los diputados en la escala izquierda-derecha es consistente con la clasificación anterior en partidos elitistas y no elitistas. En este caso, esa distinción no se ve atenuada por la religiosidad media o media alta de los diputados del PLN y el PDC. En todo caso, una combinación de estos dos criterios culturales y valorativos (religiosidad y autoidentificación ideológica) contribuye a resaltar los perfiles propios y característicos de cada uno de estos partidos.

\section{CONCLUSIONES}

Las piezas de evidencia mostradas aquí subrayan las diferencias sociales que distinguen a los partidos centroamericanos. En ese sentido, esta exploración presta una gran importancia a la interacción entre los factores de tipo socioeconómico y la evolución de las estructuras políticas e institucionales (tipos de régimen, características de los partidos, etc.). Por este motivo, este análisis no pretende reducir la vida política y las características de los partidos a ciertos rasgos sociales y económicos objetivos, los cuales explicarían los rasgos de los partidos y de cada sistema 
TABLA 8. AUTOIDENTIFICACIÓN MEDIA DE LOS DIPUTADOS EN LA ESCALA IZQUIERDADERECHA (POR PARTIDO POLÍTICO) ${ }^{5}$.

\begin{tabular}{||l|c||}
\hline $\begin{array}{l}\text { PARTIDO } \\
\text { POLÍTICO }\end{array}$ & $\begin{array}{c}\text { AUTOIDENTICACIÓN } \\
\text { IDEOLÓGICA }\end{array}$ \\
\hline ARENA & 6.8 \\
\hline PUSC & 6,2 \\
\hline PL & 6,2 \\
\hline PN & 5 \\
\hline PDC & 4.8 \\
\hline PLN & 4.4 \\
\hline FMLN & 2.9 \\
\hline FSLN & 2,6 \\
\hline
\end{tabular}

Gráfico 4. Autoidentificación ideológica

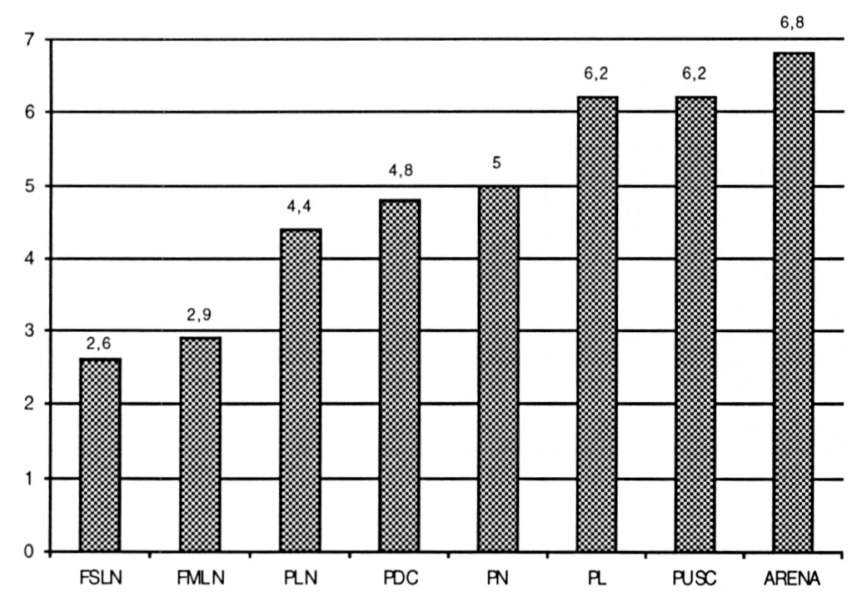

político. Por el contrario, el hecho de que la influencia entre los factores de un tipo y otro es recíproca se percibe con mayor claridad cuando constatamos que las causas de las características sociales de los partidos principales no pueden ser entendidas sin tener en cuenta la estructura de conflictos políticos surgida en cada país y los patrones de alternancia en el poder y competición electoral presentes en cada sistema político. En todo caso, este análisis pretende establecer en qué medida están presentes diferencias en las dimensiones de análisis antes mencionadas, y como aquellas se relacionan con ciertas características básicas de la evolución política de cada sociedad centroamericana. La influencia de esas dinámicas históricas resultan especialmente patentes cuando se revisan los tipos fundamentales de partidos presentes en la región.

La combinación de características que define a cada partido político permite identificar dos tipos ideales, antitéticos, de partidos políticos en Centroamérica. El primero (en el que se incluirían ARENA, el PUSC y ambos partidos hondureños) se caracterizaría por la pertenencia de sus congresistas a las clases sociales más elevadas. Este aspecto se percibe en los orígenes socioeconómicos más altos de sus integrantes, así como en las procedencias profesionales de los mismos. Estas características indican que estos partidos tienen una capacidad privilegiada para, y un interés notorio en, representar los intereses de las clases más elevadas.

En segundo lugar, este grupo de partidos se caracterizaría por el hecho de que los familiares de los congresistas participarían, en un grado superior al de otros partidos, en la vida política profesional. En este tipo de partidos, los diputados poseen conexiones políticas de carácter familiar especialmente fuertes. En este sentido, el grado de politización de su entorno familiar es relativamente alto, y también lo es su inserción en redes políticas que implican a otros familiares. Sin embargo, estos congresistas tienden a entrar en la vida política profesional en una fase más tardía. Esto tiene que ver con el hecho de que los mismos desarrollan en primer lugar sus carreras económicas y profesionales, y sólo después se integran completamente en la actividad política. Al mismo tiempo, se puede avanzar que sus ocupaciones profesionales (situadas en los estratos superiores) y sus conexiones políticas familiares tenderán a hacer especialmente suave el tránsito a la vida política.

Es interesante reseñar, en este sentido, que los congresistas de los partidos más elitistas muestran creencias religiosas especialmente intensas. Esto indica que continúa existiendo una asociación clara entre la religiosidad, el origen social y las orientaciones políticas y partidarias en Centroamérica. Esta asociación resulta especialmente reveladora si tenemos en cuenta que, en la región centroamericana, la Iglesia Católica no necesariamente ha respaldado las opciones políticas de las fuerzas políticas de orientación elitista o conservadora.

Existe una tipo alternativo de partido político en Centroamérica. Este muestra características que son opuestas a las que acabamos de enunciar. El FSLN y el FMLN son los ejemplos más claros de este tipo de partido. Sus miembros proceden de clases más bajas y entraron en la política activa en una fase mucho más temprana de sus vidas, fundamentalmente como integrantes de movimientos de protesta de masas y guerrilleros. Sus niveles profesionales son inferiores, en parte debido a su procedencia social, y en parte debido a que su entrada temprana en la vida política no les ha permitido desarrollar sus carreras profesionales. En último término, los congresistas de estos partidos se caracterizan por poseer actitudes religiosas mucho menos intensas.

Es revelador el hecho de que el FSLN ocupe posiciones más extremas en todas las dimensiones que hemos analizado. Esto puede tener que ver, en primer lugar, con el hecho de que el régimen de Somoza, marcadamente sultanista y neopatrimonial, dió lugar a una coalición revolucio-

5. Esta escala va de 1 (extrema izquierda) a 10 (extrema derecha). Las diferencias de medias entre los partidos políticos son significativas en todos los países al nivel del 0.05 . Por otra pate, la correlación simple entre los orígenes sociales de los diputados y su autoidentificación ideológica es modesta (0.25) pero claramente significativa (al 0.05). 
naria liderada por el sandinismo de caracteres más amplios y multiclasistas ${ }^{6}$. Además, es necesario tener en cuenta que el triunfo de la revolución sandinista permitió al FSLN ocupar posiciones de poder por varios años. Esto puede ayudar a explicar, por ejemplo, el hecho de que los sandinistas tengan un número de familiares activos en la vida política especialmente alto.

Finalmente, cabe hablar de algunos partidos que no se ajustan a ninguno de estos tipos ideales antitéticos. Se trata del PDC y del PLN. El PDC tiene un perfil social más cercano a las clases bajas y medias bajas, pero las orientaciones religiosas de sus congresistas son más semejantes a las de los partidos conservadores. En cuanto al PLN, sus congresistas tienen orígenes sociales más altos que los de los partidos antielitistas. Por otra parte, si bien estos partidos no representan a las élites sociales y económicas, tampoco suponen un reto a las posiciones de estas últimas semejante al protagonizado por el FSLN y el FMLN. Obviamente, este último aspecto mantiene una relación directa con las orientaciones ideológicas y políticas de cada partido.

Estas características de los partidos políticos deben ser vinculadas al sistema de partidos y al sistema político. Es especialmente importante entender el carácter de los retos experimentados por las élites sociales y políticas a fin de explicar las reacciones y actitudes de esas clases. En este sentido, es posible establecer ciertas vinculaciones entre la estabilidad política y la ausencia de retos intensos a las élites socioeconómicas. Los casos de Costa Rica y Honduras muestran que, a pesar de las importantes diferencias entre ambos países, la ausencia de retos radicales en el sistema de partidos hizo más fácil para las élites socioeconómicas aceptar formas políticas institucionales competitivas.

Por último, estos datos muestran la existencia de vínculos claros entre el origen socioeconómico de los diputados, la dinámica política de cada país y las características de su sistema de partidos. Así, se puede considerar el sistema de partidos hondureño como el más oligárquico, en la medida en que tanto conservadores como liberales tienen claras connotaciones elitistas y en que se da una clara sobrerrepresentación de los sectores empresariales en la vida parlamentaria. Además, debido a una conjunción de factores tanto históricos como de orientación de las oligarquías (Alcántara, 1990), en el marco político hondureño no han aparecido partidos de importancia que supongan un reto a la situación de predominio de las élites económicas. Estas características del sistema de partidos hondureño son consistentes con nuestros conocimientos acerca de ciertas dinámicas básicas del desarrollo político. Pues como han sostenido distintos autores, el desarrollo socioeconómico implicaría tanto una relativa diferenciación del ámbito parlamentario respecto de las estructuras de poder económico y social (expresada en la profesionalización de la élite política), como una entrada en la arena política de organizaciones que canalizan las demandas de los grupos sociales subordinados (Best, 1995; Matthews, 1985: 20).

Por su parte, los sistemas de partidos de El Salvador y Nicaragua, pese a haber seguido estos países trayectorias históricas muy diferentes, se caracterizarían por un alto grado de polarización social y política, resultado a su vez de la movilización abrupta, a partir de la década de 1970, de sectores sociales tradicionalmente subordinados y políticamente inactivos, una movilización que fue paralela a la emergencia, con modalidades peculiares a cada país, de intensos conflictos políticos y sociales. Dicha polarización se expresa, especialmente en el caso salvadoreño, en las procedencias sociales antagónicas de unos y otros actores políticos. Por una parte, partidos como ARENA reflejan un peso desorbitado de los sectores económica y socialmente más poderosos. Por otra, los parlamentarios del FSLN y especialmente del FMLN se nutren de sectores sociales de clase baja. Es interesante, a este respecto, el hecho de que estos dos últimos partidos se caractericen por una profesionalización política (revolucionaria) de sus parlamentarios mucho más temprana y pronunciada. También en este caso, la profesionalización aparece como un correlato de la incorporación a la vida política de sectores tradicionalmente subordinados y políticamente inactivos.

En este sentido, es conveniente añadir que la definición de bloques sociopolíticos marcadamente diferenciados no es necesariamente contradictoria con el establecimiento de la democracia, como no lo es la existencia de conflictos previos de notable intensidad. Por el contrario, ciertos autores han mostrado, con Rustow a la cabeza (1973), que ciertos conflictos intensos y de difícil resolución han operado a menudo como precedentes de desenlaces democráticos, desenlaces en los cuales los distintos actores se ven abocados a aceptar la existencia y participación de adversarios a los que no pueden suprimir. Además, esta dinámica no es contradictoria, en modo alguno, con la institucionalización del sistema de partidos. Por el contrario, esta última será más fuerte en la medida en que los partidos sean capaces de desarrollar fuertes vínculos con los actores sociales, vínculos que implican fuertes identidades sociopolíticas (Mainwaring y Scully, 1995: 9). Frecuentemente, esas identidades fuertes van unidas a la existencia de conflictos políticos intensos.

Finalmente, Costa Rica se caracteriza por poseer un sistema de partidos que no es ni polarizado, como en los casos de El Salvador y Nicaragua, ni netamente oligárquico, como sucede en el caso de Honduras. En Costa Rica se dan diferencias apreciables en estas dos dimensiones entre el PUSC y el PLN. Sin embargo, las mismas tienen un carácter más limitado, como se refleja en la, en todo caso, notable participación de las clases medias (incluyendo aquí a abogados y profesores) en la élite parlamentaria del PLN.

En último término, se puede afirmar que los sistemas de partidos centroamericanos reflejan, de una manera más acentuada que los de los países europeos, que se situarían por lo demás dentro de la categoría del "Estado de partidos” (Von Beyme, 1995), la estructura de poder económico de sus respectivas sociedades. En ese sentido, dichos sistemas tenderían a ser más oligárquicos (Bendel, 1995) y menos profesionalizados, caracterizados por unas relacio-

6. Sobre los regímenes sultanísticos, ver Linz (1975). Sobre las transiciones políticas desde regímenes de este tipo, ver Linz y Stepan (1996). 
nes especialmente fluidas, que en ocasiones se asemejan a una fusión, entre las élites políticas y las socioeconómicas. Sin embargo, en estos respectos se aprecian notables diferencias entre unos y otros países, y no puede ser desdeñado el hecho de que la apertura de sistemas de partidos como el nicaragüense y el salvadoreño a fuerzas sociopolíticas de procedencia muy diversa, ha modificado características fundamentales de los sistemas políticos de la región.

\section{BIBLIOGRAFÍA CITADA}

Alcántara, Manuel (1990): Sistemas politicos de América Latina (Madrid: Tecnos).

BENDEL, Petra (1995): "Democracia y partidos políticos en América Central”, en Dieter NOHLEN (comp.): Democracia y neocrítica en América Latina (Frankfurt am Main y Madrid: Vervuert e Iberoamericana).

BEST, Heinrich (1995): "European Parliamentary Elites: Cleavage Structures, Conflict Patterns and Party Systems". Ponencia presentada en la XIII sesión anual del ECPR, 27 de abril-2 de mayo, Burdeos.

Eliassen, Kjell A. (1995): The Professionalization of the Elite Recruitment. Ponencia presentada en la XIII sesión anual del ECPR, 27 de abril-2 de mayo, Burdeos.

KING, Anthony (1981): "The Rise of the Career Politician in Britain and Its Consequences", en British Journal of Political Science, vol. 11, núm. 3, págs. 249-286.

LiNZ, Juan J. (1975): "Totalitarian and Authoritarian Regimes", en Fred I. GreEnSTEIN y Nelson W. POLSBY (eds.), Handbook of Political Science, Vol. 3
(Reading et al.: Addison-Wesley Publishing Company, 1975), pp.175-411.

- y Alfred STEPAN (1996): Problems of Democratic Transition and Consolidation (Baltimore y Londres: The Johns Hopkins University Press).

Mainwaring, Scott y Timothy R. Scully (1995): "Introduction", en Scott MAINWARING y Timothy R. SCUlly: Building Democratic Institutions (Stanford: Stanford University Press).

MATTHEWs, Donald (1985): “Legislative Recruitment and Legislative Careers”, en Gerhard LOEWENBERG, Samuel PATTERSON y Malcolm E. JEWELL (eds.): Handbook of Legislative Research (Cambridge: Harvard University Press).

PuTnAm, Robert D. (1973): The Beliefs of Politicians (New Haven: Yale University Press).

RuESCHEMEYER, Dietrich, Evelyne HubER STEPHENS y John D. STEPHENS (1992): Capitalist Development and Democracy (Chicago: The University of Chicago Press).

RUOSTETSAARI, Ilkka (1995): "Transformation of the Finnish Parliamentary Elites in the 20th Century". Ponencia presentada en la XIII sesión anual del ECPR, 27 de abril-2 de mayo, Burdeos.

Rustow, Dankwart A. (1970): “Transitions to Democracy: Toward a Dynamic Model”, en Comparative Politics, vol. 2, núm. 3, Abril.

VILAS, Carlos M. (1996): "Prospects for Democratisation in a Post-Revolutionary Setting: Central America”, en Journal of Latin American Studies, vol. 28: 2.

VON Beyme, K. (1995): La clase política en el estado de partidos (Madrid:Alianza).1

\section{RESUMEN}

El artículo tiene como objeto caracterizar social y económicamente los partidos y los sistemas de partidos de cuatro países centroamericanos (Nicaragua, El Salvador, Costa Rica y Honduras), de tradición democrática dispar a través de una serie de análisis referido a sus respectivas élites parlamentarias. Dichos estudios pretenden mostrar la vinculación entre el origen socioeconómico de los diputados, sus orientaciones político-ideológicas, la dinámica política de cada país y las características de su sistema de partidos.

\section{ABSTRACT}

This article analyses some socio-economic, political and ideological characteristics of the members of parliament of four Central American countries (Nicaragua, El Salvador, Costa Rica and Honduras). This analysis tries to define the degree to which political parties have elitist or non-elitist social characteristics. On the basis of that analysis, this article distinguishes among some political party ideal-types. Finally, this article links the specific characteristics of each Central American political party to the political trajectory of each Latin American society 